\title{
A SITUAÇÃO DA CONVENÇÃO SOBRE O COMÉRCIO INTERNACIONAL DAS ESPÉCIES DA FLORA E FAUNA SELVAGENS EM PERIGO DE EXTINÇÃO - CITES - NO BRASIL: ANÁLISE EMPÍRICA
}

Gabriela Garcia Batista Lima*

\section{Resumo}

A Convenção sobre o Comércio Internacional das Espécies da Flora e Fauna Selvagens em Perigo de Extinção (CITES) consiste em um instrumento do direito internacional para a conservação ambiental e o desenvolvimento sustentável. Assume-se, no desenvolvimento do artigo, a defesa da adequação da estrutura interna de seus membros como modo de tornar efetiva a Convenção. Nessa perspectiva, discorre-se sobre o funcionamento da CITES e sobre sua importância no combate ao tráfico ilegal pertinente. Faz-se uma análise da estrutura brasileira para a realização da CITES, e com base na própria conceituação jurídica de efetividade, discutem-se os âmbitos da validade formal, da eficiência e da efetividade da Convenção no Brasil. O objetivo desta pesquisa é auferir as principais falhas sistêmicas e propor condições para concretizar, de modo mais pleno, as ações proposta pela CITES.

Palavras-chave: CITES. Direito. Ambiental. Efetividade.

\section{Introdução}

A Convenção sobre o Comércio Internacional das Espécies de Flora e Fauna Selvagens em Perigo de Extinção, conhecida como CITES ${ }^{1}$, consiste em um tratado que visa a proteger e a conservar a fauna e a flora silvestres. Com a regulamentação da comercialização internacional que envolve determinadas espécies, busca garantir que a atividade não ameace a sobrevivência ou a função ecológica da população envolvida.

O objetivo desta pesquisa, desenvolvida no âmbito do Direito Ambiental, é avaliar a efetividade da CITES no Brasil. Determinados os limites da consolidação da Convenção no contexto brasileiro, pretende-se delinear as principais falhas sistêmicas, identificando o que pode e o que deve ser reestruturado para que sua concretização se torne plena.

* Pesquisadora do UniCEUB - Brasília/DF; membro do projeto de pesquisa "Internacionalização dos Direitos". Endereço para contato: gblima@gmail.com.

1 CONVENTION on International Trade of Endangered Species. Disponível em: <www.cites. org >. Acesso em: 17 maio 2007. 
Assim, primeiro, faz-se importante compreender, ainda que brevemente, como ocorre o controle realizado pela CITES e, também, como deve ser a composição interna brasileira para estar compatível com o que foi estabelecido nesse campo. Com isso, torna-se possível a análise da efetividade da Convenção no contexto brasileiro, e geral, utilizando-se, como parâmetro, a própria conceituação jurídica de efetividade, uma vez que a Convenção é um instrumento do Direito.

\section{0 monitoramento da atividade do comércio internacional realizado pela CITES}

ACITES emergiu em um contexto delineado pela internacionalização dos problemas ambientais, até então locais ou regionais. Esses problemas surgiram quando o desenvolvimento econômico dos países se manifestava, ainda, sem qualquer medida para a conservação do meio ambiente. Diante, por exemplo, da intensidade da queima de combustíveis fósseis, da poluição da água e do ar, da destruição de florestas, evidenciou-se um estresse cumulativo dos recursos naturais.

Desse modo, a degradação ambiental agravou-se nos últimos 60 anos, em razão, principalmente, do elevado número de pessoas, com suas necessidades por refrigeração, transporte, madeira, busca por animais exóticos, acarretando a perda da biodiversidade da Terra, sem precedentes ${ }^{2}$ em termos históricos. Com a repercussão internacional de tais problemas, organizaram-se debates e criaram-se diversos instrumentos para que houvesse, em todos os ramos, ações efetivas voltadas à conservação ambiental.

Não obstante o uso de animais e de plantas silvestres ser uma prática comum há séculos, a preocupação com a diversidade ecológica passou a ser necessária a partir do momento em que o homem começou a utilizá-los como mercadorias para fins comerciais e econômicos ${ }^{3}$. Após a perda do habitat, a retirada de espécies do seu espaço para subsistência e comércio é a segunda maior ameaça à fauna e à flora silvestres ${ }^{4}$.

Destaca-se que populações de várias espécies declinaram em uma média de 40\%, entre 1970 e $2000^{5}$. Caso não se controle a exploração comercial de alguns animais e plantas,

2 PORTER, Gareth; BROWN, Janet Welsh; CHASEK, Pamela S. Global environmental politics. 3. ed. United States of America: Westview Press, 2000. p. 01-02.

3 SILVA, Geraldo Eulálio do Nascimento e. Direito ambiental internacional. 2. ed. Rio de Janeiro: Thex, 2002. p. 113.

4 REDE NACIONAL DE COMBATE AO TRÁFICO DE ANIMAIS SILVESTRES. $1^{\circ}$ Relatório Nacional sobre o Tráfico de Animais Silvestres. 2001. p. 1-108. Disponível em: <http://www.renctas.org.br/files/ REL_RENCTAS_pt_final.pdf $>$. Acesso em: 21 maio 2007.

5 THE WILDLIFE TRADE MONITORING NETWORK. What is wildife trade? When is wildife trade a problem? Disponível em: <http://www.traffic.org/wildlife/ wild6.htm>. Acesso em: 21 maio 2007. 
esse comércio, somado a outros fatores - por exemplo, a destruição do habitat - , é capaz de prejudicar, em níveis elevados, a população da espécie e, mesmo, levá-la à extinção,.

Nesse panorama, quando foi criada a CITES, o comércio internacional de recursos silvestres já existia e era realizado sem qualquer preocupação com o impacto ambiental que a atividade causava. Assim, a sua efetivação faz-se imprescindível diante da necessidade de preservação tanto dos recursos da fauna e da flora quanto das condições de existência e de adaptação dos ecossistemas e do ser humano e, ainda, diante da relevância do desenvolvimento sustentável da atividade comercial objeto de sua regulamentação.

Nesse sentido, releva-se a questão de serem a fauna e a flora, assim como os demais recursos ambientais, componentes da chamada biodiversidade ecológica. As funções exercidas por esses componentes permitem o equilíbrio ecológico em seu ecossistema. Por conseguinte, a ausência de quaisquer desses componentes afeta a composição da biodiversidade, acarretando alterações nos ecossistemas.

Assim, ainda que o objeto da Convenção se restrinja apenas à conservação e ao monitoramento das espécies e espécimes afetados pelo comércio internacional, não englobando toda fauna e flora existente, a CITES é de extrema importância para a conservação da biodiversidade. A questão é, ainda, mais complexa no que diz respeito a seu campo de atuação, pois busca-se alcançar a conservação da

biodiversidade em seus extremos, quais sejam, a ameaça de extinção de várias espécies e o comprometimento de sua função ecológica.

Deve-se salientar que o comércio da fauna e da flora silvestres constitui a base de subsistência e de desenvolvimento de muitos países, inclusive do Brasil. Nesse comércio, estão comprendidas atividades como a extração de pérolas, de madeira, de graxa de borracha, além de exportação de animais e de plantas, de pesquisas na área de medicamentos e de alimentação, entre outras. Ademais, os avanços medicinais, pelo uso e estudo de plantas e de animais silvestres que resultam na criação de produtos derivados como poções, cremes e remédios, propiciam melhor qualidade de vida ${ }^{6}$.

O desafio para a continuidade do comércio de vida selvagem nessas regiões reside na conscientização relativa ao como e ao porquê da preservação ambiental e do exercício dessa atividade de forma sustentável. Além da regulamentação, do incentivo e da criação de mecanismo para viabilizar a atividade por parte do governo, é preciso gerar, no seu complexo social e político, a referida conscientização ${ }^{7}$.

6 THE WILDLIFE TRADE MONITORING NETWORK. Traffic South América. Disponível em: <http:// www.traffic.org/network/network8.htm>. Acesso em: 21 maio. 2007.

7 Ibidem. 
A CITES é um reflexo da atenção para o desenvolvimento sustentável e exige a colaboração entre os Estados para sua consolidação, envolvendo tanto os países de importação e de exportação, como os de reexportação. A comercialização das espécies descritas somente é possível com a devida regulamentação, autorizada após um sistema de licenciamento, manuseado pelas Autoridades Administrativas e Científicas nos Estados membros. Isso importa em uma pesquisa a respeito da legalidade da origem, das condições de transporte e do impacto da atividade na população da espécie, de modo a evitar que, pela comercialização, haja afetação no equilíbrio ecológico ${ }^{8}$.

Sobre esseaspecto, esclarece-se que, para o campo do direito internacional ambiental, a questão da eficiência e mesmo da efetividade de uma Convenção como a CITES remete a discussão paraaconcretizaçãododesenvolvimentosustentável.Anecessidadederegulamentaçãoresulta, pois, não apenas da relevância da preservação ambiental, mas, também, da importância da atividade para o desenvolvimento dos países. Explica Varella que "o princípio do desenvolvimento sustentável vem da fusão de dois grandes princípios jurídicos: o do direito ao desenvolvimento e o da preservação do meio ambiente", .

Ensina Amartya Sen que desenvolvimento abrange o crescimento econômico de um país e, principalmente, a expansão de liberdade de seus cidadãos, como o acesso à saúde, à educação, ao trabalho, contemplando um sistema apto a fortalecer a estrutura de seu país tanto em termos econômicos quanto políticos ${ }^{10}$. Assim, elaborar os termos de uma Convenção internacional responsável pela regulamentação de atividades econômicas que utilizam recursos ambientais implica possibilitar, também, a própria concretização dos direitos dos cidadãos. É dizer que o esforço para o desenvolvimento define um modo sustentável na sua realização, que aposta na capacidade natural da região, valorizando os seus recursos específicos, para a satisfação das necessidades fundamentais da população em matéria de alimentação, habitação, saúde e educação, emprego, segurança, qualidade nas relações humanas. Sendo o desenvolvimento voltado para a realização do homem, sua efetividade exige um resultado satisfatório ${ }^{11}$.

Com recursos como a CITES, a sociedade possui um instrumento que orienta como deve ser a atividade, ao mesmo tempo que a promove, permitindo o desenvolvimento social e econômico. As espécies estão discriminadas em três apêndices, de acordo com o grau de proteção de que necessitam, e poderão ser comercializadas, somente, se apresentado o documento apropriado nos portos de entrada e de saída dos países. O documento é a licença

${ }^{8}$ CONVENTION ON INTERNATIONAL TRADE OF ENDANGERED SPECIES. How CITES works? Disponível em: <http://www.cites.org/eng/disc/how.shtml>. Acesso em: 21 maio 2007.

${ }^{9}$ VARELLA, Marcelo Dias. Direito internacional econômico ambiental. Belo Horizonte: Del Rey, 2003. p. 05-06.

${ }^{10}$ SEN, Amartya Kumar. Desenvolvimento como liberdade. São Paulo: Companhia das Letras, 2000. p. 17.

${ }^{11}$ SACHS, Ignacy. Ecodesenvolvimento: crescer sem destruir. São Paulo: Vértice, 1986. p. 15-16. 
emitida pelo órgão responsável pela administração da CITES, após análise, pelo órgão científico, dos impactos pertinentes.

Os requisitos para emissão da licença podem variar de acordo com a legislação dos países, mas devem estar em conformidade com as condições básicas da CITES. Do apêndice I constam espécies à beira da extinção que possam ser afetadas pelo comércio internacional, e sua comercialização é permitida, apenas, em circunstâncias excepcionais. $\mathrm{O}$ apêndice II inclui espécies que não estão em alto risco de extinção, mas sua comercialização deve ser regulamentada a fim de evitar que esse risco ocorra. No apêndice III, estão as espécies protegidas em pelo menos um país membro, o qual busca a cooperação das outras partes para assistência no controle do mercado de tais espécies ${ }^{12}$.

Percebe-se, assim, a relevância da atuação efetiva da CITES no território brasileiro e a importância do estudo para apontar as mudanças internas necessárias ao atendimento da demanda internacional do comércio da fauna e da flora. Significa, pois, possibilitar a continuidade de uma atividade que trabalha para o desenvolvimento humano, bem como conservar as condições de sobrevivência e de qualidade de vida no planeta, à medida que a Convenção proporciona, também, a conservação biológica das espécies envolvidas.

\section{A CITES como instrumento de coibição do tráfico ilegal.}

O comércio internacional monitorado pela CITES, nos anos de 1995 a 1999, abrangeu cerca de 1.5 milhões de pássaros vivos, 640.000 répteis vivos, 300.000 peles de crocodilo, 1.600 .000 de peles de lagartos, 1.100 .000 de peles de cobras, quase 300 toneladas de caviar, mais de 1 milhão de pedaços de coral ${ }^{13}$. Todavia, recursos silvestres ainda são objeto do tráfico ilegal, que ocupa a posição de terceira maior atividade ilegal no campo mundial - perdendo, somente, para o tráfico de drogas e o de armas - e movimenta de 10 a 20 milhões de dólares por ano, sendo que o Brasil participa com cerca de 5\% a 15\% do total mundial ${ }^{14}$.

A existência do tráfico ilegal da fauna e da flora silvestre continua a ser uma das principais causas à perda da biodiversidade. Com facilidade, encontram-se animais, suas partes e produtos sendo comercializados sem qualquer legalidade ou cuidado.

${ }^{12}$ CONVENTION ON INTERNATIONAL TRADE OF ENDANGERED SPECIES. How CITES works? Disponível em: <http://www.cites.org/eng/disc/how.shtml>. Acesso em: 21 maio 2007.

${ }^{13}$ THE WILDLIFE TRADE MONITORING NETWORK. What is the scale of wildlife trade? Disponível em: $<$ http://www.traffic.org/wildlife/wild2.htm>. Acesso em: 21 maio 2007.

${ }^{14}$ REDE NACIONAL DE COMBATE AO TRÁFICO DE ANIMAIS SILVESTRES. $1^{\circ}$ Relatório Nacional sobre o Tráfico de Animais Silvestres. 2001. p. 1-108. Disponível em: <http://www.renctas.org.br/files/ REL_RENCTAS_pt_final.pdf $>$. Acesso em: 21 maio 2007. 
Os contrabandistas agem em lugares de difícil patrulhamento, em fronteiras, em áreas montanhosas ou em florestas densas, e o transporte dá-se por carro, em roupas, em malas, até em containers, que são muito utilizados por não serem freqüentemente checados, devido ao grande movimento nos principais portos do país. Também fazem parte das estratégias de contrabando o uso de documentos legais para encobrir produtos ilegais e a transformação dos animais para parecerem outros ${ }^{15}$.

A dificuldade em conter o tráfico ilegal de recursos silvestres constitui-se pela falta de uma estrutura interna consolidada e fortalecida, que engloba desde a atuação do governo, quanto à fiscalização, à punição e, principalmente, à educação ambiental e aos incentivos para a legalização da atividade, até a conduta conscientizada de cada um, em sociedade, com relação ao problema., Polícia, alfândegas, autoridades judiciais, a própria sociedade, todos possuem uma visão benigna do comércio ilegal da fauna e da flora, incentivando a ilegalidade, não a punindo ou reprimindo adequadamente ${ }^{16}$.

A coibição do tráfico ilegal pela implementação da CITES dá-se em razão de a Convenção permitir e implementar uma opção de continuidade da atividade pelo uso sustentável do recurso. Todavia, é preciso que todos atuem de acordo com o que estabelece a Convenção. Não se pode admitir qualquer ilegalidade, pois fazê-lo seria admitir a destruição do meio ambiente e de qualquer possibilidade de continuidade da atividade, afinal, não se teria mais o recurso então degradado pela pressão de um mercado irregular que não respeita sua manutenção. É a opção por uma atuação consciente de que os atos presentes afetam o futuro.

\section{A CITES no Brasil}

Tratados como a CITES não são auto-executáveis e necessitam da legislação e da atuação interna, para ter efeito no nível nacional. A incorporação dos termos do tratado ao direito interno permite que a norma seja cumprida pela sociedade, garantindo sua vigência no território nacional. Nesse sentido, viabiliza não apenas o seu cumprimento, mas, também, a sua exigência por parte dos juízes e tribunais, em sua função interpretativa e aplicadora dos diplomas normativos pátrios ${ }^{17}$.

Dessa forma, tendo em vista que a CITES consiste em um instrumento regulador de uma atividade humana, focaliza-se a construção da efetividade no âmbito do Direito, o que, sob a influência do positivismo jurídico e do pós-positivismo, remonta para o estudo da efetividade da norma jurídica.

\footnotetext{
${ }^{15}$ REDE NACIONAL DE COMBATE AO TRÁFICO DE ANIMAIS SILVESTRES. $1^{\circ}$ Relatório Nacional sobre o Tráfico de Animais Silvestres. 2001. p. 1-108. Disponível em: <http://www.renctas.org.br/files/ REL_RENCTAS_pt_final.pdf>. Acesso em: 21 maio 2007.

${ }^{16}$ Ibidem.

${ }^{17}$ REZEK, José Francisco. Direito internacional público. 9. ed. São Paulo: Saraiva, 2002. p. 55-56.
} 
Sendo a norma o instrumento habilitado para regular o comportamento em sociedade, verifica-se sua regularidade no que diz respeito à validade formal, à eficácia e à efetividade propriamente dita.

Por meio dessa análise, ao se identificarem as razões, sejam morais ou sociais, de a norma estar sendo seguida ou não, é possível estruturar mecanismos para maximizar sua efetividade. Buscam-se, assim, soluções adequadas àquela realidade, o que, conseqüentemente, leva à maximização da concretização do Direito, enquanto instrumento regulador do comportamento social.

Em suma, para que as normas contidas na CITES sejam plenamente executáveis, devem estar regularmente inseridas na legislação interna e, para serem plenamente exigíveis, o ordenamento jurídico interno deve criar instrumentos, em obediência aos termos da Convenção. Com isso, pode-se verificar se o Estado-membro está cumprindo os termos com os quais se obrigou internacionalmente.

\subsection{Validade formal}

No ensinamento de Norberto Bobbio, para a averiguação da validade formal da norma jurídica, é necessária a verificação de todos os aspectos do processo normativo: se a autoridade de quem ela emanou possuía legitimidade; se a norma e a competência para institucionalizá-a são congruentes com a norma fundamental do seu ordenamento jurídico; e se a norma ainda é válida em seu aspecto temporal, ou, pelo contrário, se seu prazo estabelecido exauriu, ou foi revogada por outra, ou passou a ser incompatível com outras normas do sistema ${ }^{18}$.

Como se pode ilustrar com a CITES, tem-se, como prática dominante no eixo mundial, a atuação do direito internacional convencional, habilitado para promover o desenvolvimento do direito entre Estados. A validade formal de um tratado consiste em verificar se a sua constituição ocorreu nos moldes legitimados, no campo internacional e na ocasião de sua inserção no ordenamento jurídico interno. No modelo clássico do direito internacional, em geral, são quatro as fases pelas quais têm de passar os tratados solenes, até sua conclusão: negociações preliminares, assinatura ou adoção pelo Executivo, aprovação parlamentar por parte de cada Estado interessado e ratificação ou adesão do texto convencional ${ }^{19}$.

Para um tratado ser válido, é necessário que as partes tenham capacidade jurídica para tanto, que os agentes estejam habilitados para os atos pertinentes e que haja um consentimento mútuo ${ }^{20}$. Com o consentimento, que consiste na assinatura, o vínculo

\footnotetext{
${ }^{18}$ BOBBIO, Norberto. Teoria da norma jurídica. São Paulo: EDIPRO, 2001. p. 47.

${ }^{19}$ MAZZUOLI, Valério de Oliveira. Tratados internacionais. São Paulo: J. Oliveira, 2001. p. 37.

${ }^{20}$ SILVA, Geraldo Eulálio do Nascimento; ACCIOLY, Hidebrando. Manual de direito internacional público. 15. ed. São Paulo: Saraiva, 2002. p. 30.
} 
jurídico é formado, e o tratado tem condições de vigência imediata. No entanto, caso as partes prefiram delongar a vigência por tempo certo, o que consiste na vacatio legis, somente depois de decorrido o lapso temporal pactuado, o tratado torna-se vigente, entrando em vigor, para, então, poder incidir ${ }^{21}$. E tem-se a ratificação, que é o ato unilateral com que o signatário de um tratado exprime, definitivamente, no campo internacional, sua vontade de obrigar-se ${ }^{22}$.

No âmbito internacional, a CITES surgiu dos primeiros esboços apresentados em 1960, na $7^{\mathrm{a}}$ Assembléia Geral da União Mundial para a Conservação da Natureza (IUCN) ${ }^{23}$. Em 1972, durante a Conferência de Estocolmo, foi aprovada uma recomendação, ratificando o projeto da Convenção, celebrado no ano de 1973, em Washington, com a participação de 88 países ${ }^{24}$.

No Brasil, depende da aprovação do Congresso Nacional a ratificação de tratados que acarretem encargos ou compromissos gravosos ao patrimônio nacional. Essa aprovação é prevista constitucionalmente e dá-se, mediante Decreto Legislativo. Após a ratificação, o tratado será promulgado, ato privativo do Presidente da República, e, por fim, será publicado no Diário Oficial da União, tornando-se válido e executável, com força de lei nacional.

O Brasil aderiu à CITES em 1973. Formalmente inserida na legislação interna, quando da sua ratificação, em 24 de junho de 1975, pelo Decreto Legislativo ${ }^{\circ}$ 54, promulgado pelo Decreto $n^{\circ} .76 .623$ de 1975, entrou em vigor 90 dias após o ato. Sua ratificação e promulgação deram-se, portanto, nos moldes constitucionais, legitimando a sua validade formal: O Presidente da República promulgou a CITES, para que fosse a Convenção executada e cumprida, nos termos em que foi concluída, havendo o Congresso Nacional aprovado a Convenção, pelo Decreto Legislativo $n^{\circ}$ 54. A Convenção entrou em vigor, para o Brasil, em 04 de novembro de 1975, e, posteriormente, foi alterada pelo Decreto Legislativo $\mathrm{n}^{\circ}$. 35, em 1985, e tal alteração, promulgada pelo Decreto $\mathrm{n}^{\mathrm{o}} .92 .446$, de 07 de março de $1986^{25}$.

\subsection{Eficácia}

Não basta, apenas, a validade formal estar regularizada para que se verifique a consolidação de uma norma. É preciso, também, auferir sua real capacidade de produzir seus efeitos e sua produção efetiva; para isso, remonta saber se a norma tem condições fáticas e técnicas de atuar, é a verificação do âmbito da eficácia da norma jurídica ${ }^{26}$.

\footnotetext{
${ }^{21}$ REZEK, José Francisco. Direito internacional público. 9. ed. São Paulo: Saraiva, 2002. p. 33-47.

${ }^{22}$ Ibidem, p. 50-54.

${ }^{23}$ THE WORLD CONSERVATION UNION. [Home page]. Disponível em: <http://www.iucn.org/>. Acesso em: 17 maio 2007.

${ }^{24}$ MINISTÉRIO DO MEIO AMBIENTE. Instituto Brasileiro do Meio Ambiente e dos Recursos Naturais Renováveis (IBAMA). Plano de ação GT-CITES. Brasília, 2005. p. 3-4.

${ }^{25}$ Ibidem, p. 4.

${ }^{26}$ FERRAZ JUNIOR, Tercio Sampaio. Introdução ao estudo do direito: técnica, decisão, dominação. São Paulo: Atlas, 1988. p. 181.
} 
Segundo a Convenção, todo ato comercial internacional de espécies nela descritas deve ser autorizado por um sistema de licenciamento, controlado pelos órgãos Administrativo e Científico, designados por cada Estado-membro. No Brasil, o órgão Administrativo e Científico designado para efetivar a CITES é o IBAMA, que atua por suas Diretorias, Coordenações e Unidades Especializadas, papel dividido, atualmente, entre a Diretoria de Florestas e a Diretoria de Fauna e Recursos Pesqueiros, para espécies da flora e fauna, respectivamente ${ }^{27}$.

Enquanto autoridade administrativa, o referido órgão é responsável por elaborar relatórios periódicos, devolver espécies e espécimes apreendidos ao país de origem, registrar infratores, emendas, inclusões e transferências aos apêndices da CITES, dentre outras funções. Atualmente, existem 11 autoridades administrativas, que não trabalham exclusivamente com a CITES $^{28}$.

Por outro lado, compete à autoridade científica avaliar e comprovar que o comércio da espécie alvo não trará resultados negativos, a propósito dos aspectos pertinentes relacionados à função e à sobrevivência. Os resultados devem ser informados à autoridade administrativa, para facilitar a adoção de medidas necessárias à devida preservação. Com base nisso, define-se o funcionamento de sua cadeia de produção. Foram designadas, na estrutura do IBAMA, como autoridades científicas, suas Unidades Especializadas, que tratam da fauna e da flora, comportando as espécies da CITES.

Para a fauna, existem: Centro de Pesquisa para a Conservação de Aves Silvestres (CEMAVE); Centro Nacional de Pesquisa para a Conservação de Predadores Naturais (CENAP); Centro de Conservação de Manejo de Répteis e Anfíbios (RAN); Centro Nacional de Conservação e Manejo das Tartarugas Marinhas (TAMAR); Centro de Proteção de Primatas Brasileiros (CPB); Centro Nacional de Pesquisa, Conservação e Manejo de Mamíferos Aquáticos ${ }^{29}$.

Existem, ainda, Centros de Pesquisa e Gestão de Recursos Pesqueiros do Litoral para as Regiões do Norte, Nordeste, Sudeste e Sul e Centro de Pesquisa e Gestão de Recursos Pesqueiros Continentais. Para a flora, destacam-se: Centro Nacional de Orquídeas, Plantas Ornamentais, Medicinais e Aromáticas (COPOM); Laboratório de Produtos Florestais (LPF); Coordenação Geral de Gestão de Recursos Florestais (CGREF); Centro Nacional de Apoio ao Manejo Florestal ${ }^{30}$.

Contudo, importa destacar que o estudo do impacto ambiental se torna limitado à extensão técnica e de localização das Unidades Especializadas que, por vezes, ou não possuem

\footnotetext{
${ }^{27}$ MINISTÉRIO DO MEIO AMBIENTE. Instituto Brasileiro do Meio Ambiente e dos Recursos Naturais Renováveis (IBAMA). Plano de ação GT-CITES. Brasília, 2005. p. 3.

${ }^{28}$ Ibidem, p. 7

${ }^{29}$ Ibidem, p. 8.

${ }^{30}$ Ibidem, p. 8-9.
} 
todo o conhecimento científico, ou não chegam ao local pertinente para a investigação. Não há, no Brasil, qualquer colaboração ou ajuda de entidades não governamentais para apoiar na concretização da CITES, como existe em outros países.

O procedimento orientado pela CITES, adaptado ao contexto brasileiro, em suma, segue da necessidade da regulamentação e do incentivo para a implementação de criadouros especializados, no que se refere à fauna, e de empresas regularizadas para a flora, haja vista restrições legais internas. Ademais, são instrumentos as regulamentações sobre modo de proceder da comercialização, sobre educação ambiental, sobre fiscalização e sobre punição, além da regulamentação quanto ao destino dos recursos apreendidos.

Em termos de instrumentos normativos, na verificação da existência de elementos para a execução da CITES, ressalta-se o Decreto ${ }^{\circ} 3.607$, de 2000, que implementou a Convenção de modo objetivo, vinte e cinco anos depois de sua vigência no Brasil. Contudo, mesmo antes desse Decreto, a Convenção já vinha sendo contemplada pelo IBAMA. Destacam-se, também, a Portaria $\mathrm{n}^{\mathrm{o}}$. 102/98, que regulamenta os criadouros de animais da fauna silvestre exótica com fins econômicos e industriais, e a Portaria $n^{\circ}$. 118/97, que regulamenta os criadouros de animais da fauna silvestre brasileira, seus produtos e subprodutos, voltados para fins comerciais e industriais.

A Portaria $n^{\circ}$. 117/97 dispõe sobre a comercialização de animais vivos, abatidos, de partes e de produtos da fauna brasileira, provenientes de criadouros, com finalidade econômica e industrial, e de jardins zoológicos registrados junto ao IBAMA. Já a Portaria nº. 93/98, também responsável pela regulamentação da comercialização, dispõe sobre o ato de importação e de exportação de espécimes vivos, de produtos e de subprodutos da fauna silvestre e exótica brasileiras.

Há, ainda, a Instrução Normativa $n^{\circ}$. 02/01, de 2001, que dispõe sobre a obrigatoriedade na identificação individual de espécimes da fauna, para fins de controle de criação e de comércio, e a Portaria $n^{\circ}$. 113/97. Para os recursos pesqueiros, destacam-se a Instrução Normativa $n^{\circ} .56 / 2004$, que estabelece normas para utilizar peixes ornamentais marinhos, e a Instrução Normativa $\mathrm{n}^{\circ}$. 13/2005, que estabelece normas para a utilização de peixes ornamentais de águas continentais. Apontam que, ao se tratar de espécies CITES, a comercialização deve corroborar com toda a regulamentação desta.

Para a flora, existem a Portaria $\mathrm{n}^{\circ} .112 / 1985$, que regulamenta a coleta, transporte, comercialização e industrialização de plantas ornamentais, medicinais, aromáticas ou tóxicas, a Portaria $n^{\circ} .83 / 1996$, que regulamenta a exportação de produtos e subprodutos oriundos da flora brasileira, e a Instrução Normativa $n^{\circ} .03 / 2004$, que estabelece procedimentos para a emissão de licenças - CITES. 
Dessa forma, no caso de espécies veiculadas pela CITES, deve o comerciante estar em conformidade com o Decreto $n^{0} 3.607 / 00$, que dispõe sobre a implementação da CITES, e, conseqüentemente, com o Decreto $n^{0} .76 .623 / 75$, que promulga a Convenção, logicamente que inseridas as alterações do Decreto Legislativo n ${ }^{\circ}$. 35, em 1985, promulgado pelo Decreto nº 92.446, de 07.03.1986.

Para o infrator, constitui crime matar, caçar, apanhar, utilizar espécimes da fauna silvestre sem a devida permissão, licença ou autorização da autoridade competente, ou em desacordo com a obtida, conforme a Lei $n^{\circ}$. 9.605/1998. A pena deverá corroborar, também, com a Lei nº. 6.938/1981, sendo prevista, ainda, sanção administrativa, conforme Decreto no ${ }^{\circ}$.3.179/1999. Aqui, identifica-se a relevância da atuação do judiciário para implementação da CITES, pois, no momento da formulação da punição, possui a oportunidade de influenciar no comportamento social dos infratores, podendo propiciar-lhes o máximo de esclarecimento quanto à importância da não repetição daquele crime.

\subsection{Efetividade}

Presentes os instrumentos de execução, é essencial verificar se a sociedade está cumprindo as regras de tais instrumentos e atuando conforme a Convenção. Ainda que a norma esteja apta para a produção de seus efeitos, sendo essa aptidão caracterizada pela regularidade na questão da validade formal, e que existam os meios para a sua incidência, isso não significa que eles, realmente, ocorrerão.

Discute-se, aqui, a regra jurídica enquanto momento da conduta humana, de forma que a sociedade deve reconhecer o Direito, incorporando-o à sua maneira de ser e de agir. Nesse sentido, quando as normas legais contrariam as tendências e inclinações dominantes no seio da coletividade, somente poderão vir a ser executadas de maneira compulsória, não possuindo um cumprimento natural, sem resistência, por parte da coletividade ${ }^{31}$.

Na verificação da conduta propriamente dita, uma das principais peculiaridades do contexto brasileiro consiste no fato de que não há grandes exportadores e importadores de recursos naturais. Isso dificulta a implementação da Convenção, pois, no Brasil, somente pode fazer parte do comércio a espécie oriunda de cativeiro legalizado, que são os criadouros.

No Brasil, para o mercado de importação e de exportação, apesar da grande demanda, o número de exportadores e importadores registrados junto ao IBAMA é pequeno. Constam, na Lista de Exportadores registrados no IBAMA, cerca de 50 criadouros ativos ${ }^{32}$, até 2003, quando foi feita sua última atualização. Desses, apenas 15 possuem os dados plenamente definidos. Constam, na Lista de Importadores $^{33}$, também atualizada em 2003, cerca de 90 registros ativos junto ao IBAMA, sendo que, desses, cerca de 50, somente, possuem os dados completos.

\footnotetext{
${ }^{31}$ REALE, Miguel. Lições preliminares de direito. 27. ed. São Paulo: Saraiva, 2003. p. 112.

${ }^{32}$ MINISTÉRIO DO MEIO AMBIENTE. Instituto Brasileiro do Meio Ambiente e dos Recursos Naturais Renováveis (IBAMA). Lista de exportadores ativos junto ao IBAMA. Disponível em: $<\mathrm{http} / / \mathrm{www}$. ibama.gov.br/fauna/criadouros/ exportadores.pdf >. Acesso em: 04 mar. 2007.

${ }^{33}$ Ibidem.
} 
É necessário maior incentivo para tornar o mercado mais expressivo no território brasileiro, com a presença de grandes importadores e exportadores especializados nas espécies e espécimes CITES. Comporta entender que haverá a emissão de licenças somente para aquelas espécies e espécimes com todo um contexto legalizado. Dessa forma, a emissão de licenças é, então, limitada, diante da estrutura que tem a atividade até o momento da importação, exportação, reexportação ou introdução procedente do mar.

Nesse aspecto, além da falta de incentivo, por parte do governo, para o estabelecimento de criadouros legalizados, falta, também, atuação mais efetiva no campo da educação ambiental, propiciando informações suficientes para modificar o comportamento social, de modo que as próprias pessoas passem a exigir legalidade na atividade, conscientizadas da importância da conservação da biodiversidade. $\mathrm{Na}$ investigação da reação da sociedade brasileira, com relação ao quadro alarmante, percebido no contexto nacional, para a consolidação da CITES, constatou-se uma conscientização, ainda que tardia, a respeito da necessidade de reestruturação dos aspectos de implantação da Convenção.

$\mathrm{Na}$ esfera da educação ambiental, com o Programa Nacional de Educação Ambiental (PRONEA), iniciado em 1994, houve inúmeras ações educativas realizadas com grupos sociais relacionados a atividades de gestão ambiental. Desde então, busca-se criar condições para a participação individual e coletiva nos processos decisórios sobre acesso e uso dos recursos ambientais no Brasil ${ }^{34}$. A atitude é positiva e necessária em termos de buscar uma maior efetividade. Contudo, revela-se, ainda, insuficiente, no que se refere à implementação da CITES, dados os aspectos até então verificados.

No que se refere à comercialização, buscou-se fortalecer o sistema de registro das espécies e dos espécimes envolvidos, que é a própria garantia da legalidade do respectivo recurso. Nesse sentido, houve grande avanço na coibição do tráfico ilegal devido à alteração do sistema de registro de transporte de Produtos Florestais. A Autorização de Transporte de Produtos Florestais (ATPF) foi substituída pelo Documento de Origem Florestal (DOF), que funciona, integralmente, por meio eletrônico. Foi um golpe no crime organizado, que se especializara em falsificar e comprar guias de papel do antigo sistema para o comércio ilegal de madeiras e de carvão vegetal, principalmente ${ }^{35}$. Assim que o DOF entrou em operação, o IBAMA detectou tentativas de fraude, por exemplo, de empresas que tentaram falsificar declarações de estoque de madeira em quantidades superiores às

${ }^{34}$ MINISTÉRIO DO MEIO AMBIENTE. Instituto Brasileiro do Meio Ambiente e dos Recursos Naturais Renováveis (IBAMA). Relatório de Atividades da Coordenação Geral de Educação Ambiental - Cgeam/ Disam: 2003-2006. Disponível em: <http://www.ibama.gov.br/cgeam/ download.php?id_download= 7>. Acesso em: 21 maio 2007.

${ }^{35}$ AMADOR, Rubens; SATO, Sandra; MOTTA, Luiz da. DOF: O big brother do transporte florestal. Revista Ibama, Brasília, v. 2, n. 2, p. 28-31. 
verificadas no pátio das madeireiras, e a descoberta do delito deu-se cinco dias após a vigência daquele Documento, comprovando a eficiência do sistema ${ }^{36}$.

O IBAMA, em 2004, criou o Grupo de Trabalho CITES - GT-CITES, formalmente constituído pela Portaria ${ }^{\circ}$. 22 de abril de 2005, com o objetivo de fortalecer e adaptar toda a composição interna brasileira, desde maior integração interna e capacitação dos agentes, até a viabilização da descentralizaçãodosistemadelicenciamentodaCITESpara outrasunidades doIBAMA, estrategicamente montadas nos lugares com maior demanda pela fauna e pela flora. Atualmente, a emissão de licenças ocorre, somente, em Brasília, o que acarreta menor alcance da efetividade da Convenção, tendo em vista a rapidez que o sistema exige, a fim de que haja a conservação do recurso ${ }^{37}$.

No que tange à fiscalização, é importante ressaltar a intensificação das ações da polícia federal, com a colaboração do Ministério do Meio Ambiente, do IBAMA e de entidades dos países das principais fronteiras, na coibição do tráfico ilegal. No contexto da flora, 292 toras de cedro e mogno, além de 957 pranchas dessas espécies, foram apreendidas em 2006, só nessas operações. Nesse aspecto, as fronteiras são os principais focos para o tráfico ilegal ${ }^{38}$.

Outro elemento é a expansão da quantidade de Centros de Triagens de Animais Silvestres, locais de estada dos animais vivos apreendidos. Atualmente, são 42 CETAS espalhados pelas cinco regiões brasileiras, e o IBAMA, visando a triplicar esse número, vem articulando-se, com o Projeto CETAS Brasil, para construir 117 novas unidades, distribuídas, estrategicamente, por onde há maior número de apreensões ${ }^{39}$.

Na esfera da punição dos infratores, há de se ressaltar que as disposições existentes não parecem estar adequadas à gravidade da infração, pois há uma interferência agressiva nas condições funcionais do ambiente, enquanto mantedor da biodiversidade e do equilíbrio ecológico. Isso implica, necessariamente, a não efetividade da CITES, em termos de se evitar que a conduta venha a ocorrer novamente.

De acordo com a Lei no $.9 .605 / 1998$, a pena para os crimes contra a fauna e contra a flora varia conforme o potencial ofensivo da ação danosa. Por exemplo, relativamente à fauna, em caso de matar, apanhar, vender, exportar ou adquirir de forma ilegal, a pena é de detenção de seis meses a um ano e multa, aumentada de metade, quando a espécie estiver ameaçada de extinção, conforme $\S^{\circ}$ do art. 29. Exportar peles e couros de anfíbios e répteis em bruto, sem autorização competente, incorre em reclusão de um a três anos e multa (art. 30).

\footnotetext{
${ }^{36}$ AMADOR, Rubens; SATO, Sandra; MOTTA, Luiz da. DOF: O big brother do transporte florestal. Revista Ibama, Brasília, v. 2, n. 2, p. 28-31.

${ }^{37}$ MINISTÉRIO DO MEIO AMBIENTE. Instituto Brasileiro do Meio Ambiente e dos Recursos Naturais Renováveis (IBAMA). Plano de ação GT-CITES. Brasília, 2005. p. 10.

${ }^{38}$ MACEDO, Kézia. A última fronteira do crime ambiental. Revista Ibama, Brasília, v. 2, n. 2, p. 17.

${ }^{39}$ MOTTA, Luiz da. CETAS: expansão da rede de triagem de animais silvestres. Revista Ibama, Brasília, v. 2 , n. 2 , p. 39.
} 
Segundo o art. 32, havendo abuso e maus tratos aos animais, a pena de detenção é de três meses a um ano e multa, sendo aumentada de um sexto a um terço se ocorre a morte. Cumpre perceber que a prática de maus tratos aos animais é uma das principais colaboradoras para a extinção das espécies e para a conseqüente afetação na biodiversidade mundial. Contudo, a pena consiste somente na detenção de três meses a um ano, o que não demonstra, por parte do Estado, o esperado reconhecimento da tamanha gravidade da conduta.

No âmbito da flora, a situação é diferente. Por exemplo, descreve o art. 39 que danificar floresta de preservação permanente resulta em pena de detenção de um a três anos ou multa, ou ambas as penas cumulativamente; causar dano às Unidades de Conservação concorre para reclusão de um a cinco anos; e afetar espécies ameaçadas de extinção considera-se circunstância agravante. Se o crime for culposo, a pena será reduzida à metade.

Por vezes, a legislação penal ambiental parece suficiente, por vezes não, e, na maioria dos casos, a aplicação da pena segue a Lei dos Juizados Especiais Cíveis e Criminais, Lei no . 9.099/1995, no âmbito da Justiça Estadual, e, dependendo das circunstâncias do crime, aplica-se a Lei dos Juizados Criminais Federais, de $n^{\circ}$. 10.259/2001, observadas as alterações da Lei $n^{\circ}$. 11.313/2006.

De modo geral, a crítica manifestada diz respeito à aplicação de penas inadequadas à punição de um crime ambiental. Ao invés de penas privativas de liberdade, aplicam-se penas alternativas e restritivas de direito, instituídas pelos referidos diplomas processuais. Estas não parecem apropriadas à função de conscientização da realidade da gravidade do dano ambiental. Ocorre, ainda e eventualmente, a suspensão do processo, nos termos do artigo 89 da Lei 9.099/1995, quando a pena mínima cominada é igual ou inferior a um ano.

\section{Conclusão}

A estrutura brasileira ainda é insuficiente no que se refere à efetivação da Convenção. É necessário maior incentivo na regulamentação de toda a atividade, para propiciar maior segurança jurídica e ambiental quanto à emissão de licença e à efetiva atuação da fiscalização, na identificação dos produtos nos portos e aeroportos do país.

Contudo, haja vista a atuação do IBAMA, na implementação do GT-CITES e na expansão dos CETAS, e a atuação da polícia federal, no trabalho de identificação contínua dos mecanismos utilizados por traficantes, percebem-se integração e movimentação significativas, fundamentadas na conscientização da relevância da conservação da biodiversidade. Revela-se, então, a preocupação com a melhoria do funcionamento da CITES na maioria de seus aspectos, como um sistema de licenciamento e um sistema de conservação das espécies envolvidas e afetadas pelo comércio internacional. 
Todavia, outras mudanças fazem-se, ainda, necessárias, conforme já ressaltado. Uma delas é o incentivo à instituição de criadouros, para que se tenha, no contexto brasileiro, um mercado expressivo e capaz de comportar toda a demanda que impõe o campo internacional, para a manutenção da atividade pela CITES. Outras são a conscientização mais efetiva por parte da sociedade e a revisão da legislação pertinente à punição dos infratores, para maior sensibilização a respeito da identificação da gravidade de uma conduta contra o meio ambiente.

Na busca por reestruturação, propiciam-se, também, condições para o país posicionar-se melhor acerca da implementação da Convenção no âmbito internacional, principalmente quando das propostas de inclusão ou de exclusão de espécies e espécimes nos Apêndices. Dessa maneira, toda ação implicará a ciência de que a estrutura brasileira comporta instrumentos hábeis para suportar imposições feitas, desde a existência de instituições especializadas para fornecer a espécie ou o espécime com a origem legalizada, até a atuação efetiva da fiscalização.

Não obstante haver previsão legal e atuação do Estado, regulamentando todo o procedimento interno, até a comercialização internacional propriamente dita, é importante que a sociedade se conscientize da necessidade da conservação ambiental e da relevância da conduta de cada indivíduo para a efetivação dessa proteção, em todas as etapas da atividade. A conscientização referente aos termos da CITES para a conservação ambiental acarretaria maior coibição, por parte da sociedade, do tráfico ilegal, pois seus membros sequer admitiriam feiras e criadouros ilegais ou comprariam produtos de origens duvidosas.

Dessa forma, percebe-se a importância da mobilização da sociedade para a efetivação da Convenção. De nada adiantam incentivo e atuação por parte do governo, se a coletividade não cumpre e não exige a atividade legalizada e adequada à conservação ambiental..

\title{
The situation of the convention on international trade of endangered species - CITES - in Brazil: empirical analysis
}

\begin{abstract}
The Convention on International Trade of Endangered Species (CITES) is an instrument of the international law to the ambient conservation and the sustainable development, and for your execution, needs all an adjusted in the nacional structure of its members. After an understanding of the functioning and the importance of the CITES for the combat to the pertinent illegal traffic, the present research verifies how is the Brazilian structure for the accomplishment of CITES, and analyzes, with fulcrum in the legal conceptualization of effectiveness, the scopes of the formal validity, the efficiency and the effectiveness of the
\end{abstract}


Convention in Brazil, in order to identify the main imperfections on the system, propitiating conditions for a greater fullness in its concretion.

Keywords: CITES. Environmental Law. Effectiveness.

\section{Referências}

AMADOR, Rubens; SATO, Sandra; MOTTA, Luiz da. DOF: O big brother do transporte florestal. Revista Ibama, Brasília, v. 2, n. 2, p. 28-31.

BOBBIO, Norberto. Teoria da norma jurídica. São Paulo: EDIPRO, 2001.

CONVENTION on International Trade of Endangered Sspecies. Disponível em: <www.cites. org $>$. Acesso em: 17 maio 2007.

CONVENTION ON INTERNATIONAL TRADE OF ENDANGERED SPECIES. How CITES works? Disponível em: <http://www.cites.org/eng/ disc/how.shtml>. Acesso em: 21 maio 2007.

FERRAZ JUNIOR, Tercio Sampaio. Introdução ao estudo do direito: técnica, decisão, dominação. São Paulo: Atlas, 1988.

MINISTÉRIO DO MEIO AMBIENTE. Instituto Brasileiro do Meio Ambiente e dos Recursos Naturais Renováveis (IBAMA). Lista de exportadores ativos junto ao IBAMA. Disponível em: <http://www.ibama. gov.br/fauna/criadouros/exportadores.pdf > . Acesso em: 04 mar. 2007.

. Plano de Ação GT-CITES. Brasília, 2005.

. Relatório de atividades da coordenação geral de educação ambiental-Cgeam/Disam: 2003-2006. Disponível em: $<$ http://www.ibama.gov.br/cgeam/download.php?id download=7 $>$. Acesso em: 21 maio 2007.

MACEDO, Kézia. A última fronteira do crime ambiental. Revista Ibama, Brasília, v. 2, n. 2, p.17.

MAZZUOLI, Valério de Oliveira. Tratados internacionais. São Paulo: J. Oliveira, 2001.

MOTTA, Luiz da. CETAS. Expansão da rede de triagem de animais silvestres. Revista Ibama, Brasília, v. 2, n. 2, p. 39.

PORTER, Gareth, BROWN, Janet Welsh; CHASEK, Pamela S. Global environmental politics. 3. ed. United States of America: Westview Press, 2000.

REALE, Miguel. Lições preliminares de direito. 27. ed. São Paulo: Saraiva, 2003.

REDE NACIONAL DE COMBATE AO TRÁFICO DE ANIMAIS SILVESTRES. $1^{\circ}$ Relatório Nacional sobre o Tráfico de Animais Silvestres. 2001. Disponível em: <http://www.renctas.org. br/files/REL_RENCTAS_pt_final.pdf>. Acesso em: 21 maio 2007. 
REZEK, José Francisco. Direito internacional público. 9. ed. São Paulo: Saraiva, 2002.

SACHS, Ignacy. Ecodesenvolvimento: crescer sem destruir. São Paulo: Vértice, 1986.

SEN, Amartya Kumar. Desenvolvimento como liberdade. São Paulo: Companhia das Letras, 2000 .

SILVA, Geraldo Eulálio do Nascimento e. Direito ambiental internacional. 2. ed. Rio de Janeiro: Thex, 2002.

SILVA, Geraldo Eulálio do Nascimento; ACCIOLY, Hidebrando. Manual de direito internacional público. 15. ed. São Paulo: Saraiva, 2002.

THE WILDLIFE TRADE MONITORING NETWORK. Traffic South América. Disponível em: $<$ http://www.traffic.org/network/network8.htm>. Acesso em: 21 maio 2007.

. What is the scale of wildlife trade? Disponível em: <http://www. traffic.org/wildlife/ wild2.htm>. Acesso em: 21 maio 2007.

. What is wildlife trade? When is wildlife trade a problem? Disponível em: $<$ http://www. traffic.org/wildlife/wild6.htm>. Acesso em: 21 maio 2007.

THE WORLD CONSERVATION UNION. [Home page]. Disponível em: $<$ http://www.iucn.org/>. Acesso em: 17 maio 2007.

VARELLA, Marcelo Dias. Direito internacional econômico ambiental. Belo Horizonte: Del Rey, 2003. 